Supporting Information

\title{
Morphological Variations of Explosive Residue Particles and Implications for Understanding Detonation Mechanisms.
}

Nadia Abdul-Karim, ${ }^{* \S}$ Christopher S. Blackman, ${ }^{\S}$ Philip P. Gill, ${ }^{\ddagger}$ Ruth M. Morgan, Lidija Matjacic, ${ }^{ \pm}$ Roger Webb ${ }^{ \pm}$and Wing H. Ng. ${ }^{\Phi}$

${ }^{\S}$ Christopher Ingold Laboratories, Department of Chemistry, University College London, 20 Gordon Street, London, WC1H 0AJ, UK. nadia.abdul-karim.10@ucl.ac.uk

${ }^{¥}$ Centre for Defence Chemistry, Cranfield University, Defence Academy of the United Kingdom, Shrivenham, SN6 8LA, UK.

${ }^{\ddagger}$ Centre for the Forensic Sciences, Department of Security and Crime Science, University College London, 35 Tavistock Square, London, WC1H 9EZ, UK.

${ }^{ \pm}$Surrey Ion Beam Centre, Nodus Laboratory, University of Surrey, Guildford, Surrey, GU2 7XH, UK.

$\Phi$ Department of Electronic and Electrical Engineering, Faculty of Engineering Sciences, University College London, Torrington Place, WC1E 7JE, UK.

\section{Table of contents}

Section 1. Images of heterogeneous explosive residues deposition......................... S-2

Section 2. Aluminised Ammonium Nitrate: EDS analysis.............................

Raman spectroscopy.............................. -4

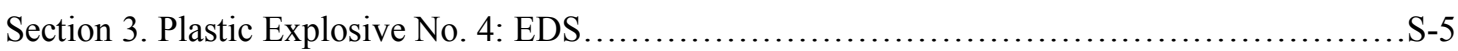



HPLC-MS ................................................

Section 4. Quantification of post-blast explosive residues: Particle size distribution...............S-9

Chromatographic quantification of residues.............S-11 


\section{Section 1. Heterogeneous Explosive Residue Deposition}

Figure S-1 is a set of micrographs of stub surfaces collected from different distances from the detonations of $0.5 \mathrm{~kg} \mathrm{AlAN}$ and PE4 charges that show the residue particles were heterogeneously deposited onto surfaces. Whilst other particle types were present on the stubs (such as sediment particles) only those ascribed to be explosive residues were focused upon for further analyses (indicated by the elemental compostion and confirmatory techniques applied, see SI sections 2 and 3). In order to locate the relevant particles, each SEM stub surface was scanned from side to side, top to bottom. The average scan time for the stubs positioned closest to the detonations $(1 \mathrm{~m}, 2 \mathrm{~m}$, and $3 \mathrm{~m}$ away) was 45 to 60 minutes. For those stubs positioned further than $3 \mathrm{~m}$ from the firings of each explosive type, the average scan time was 20 to 30 minutes due to there being fewer particles present on them.

Figure S-1. Representative SEM micrographs of stub surfaces collected from distances of a) $1 \mathrm{~m}, \mathrm{~b}$ ) 2 $\mathrm{m}$ and c) $4 \mathrm{~m}$ from $0.5 \mathrm{~kg}$ AlAN charge firings; and d) $4 \mathrm{~m}$ from PE4 firings.






\section{Section 2. Aluminised Ammonium Nitrate}

\section{EDS analysis}

Only nitrogen and oxygen were detected in the EDS spectra of the AN prill as expected (Figure S-2); typically the ratio between the atomic percentage of nitrogen detected $(36.7 \%)$ and oxygen $(63.3 \%)$ was consistent with the theoretical ratio of $\mathrm{N}: \mathrm{O}(2: 3)$ in $\mathrm{NH}_{4} \mathrm{NO}_{3}$.

Figure S-2. EDS spectrum of AN prill (SEM micrograph inset) prior to grinding.

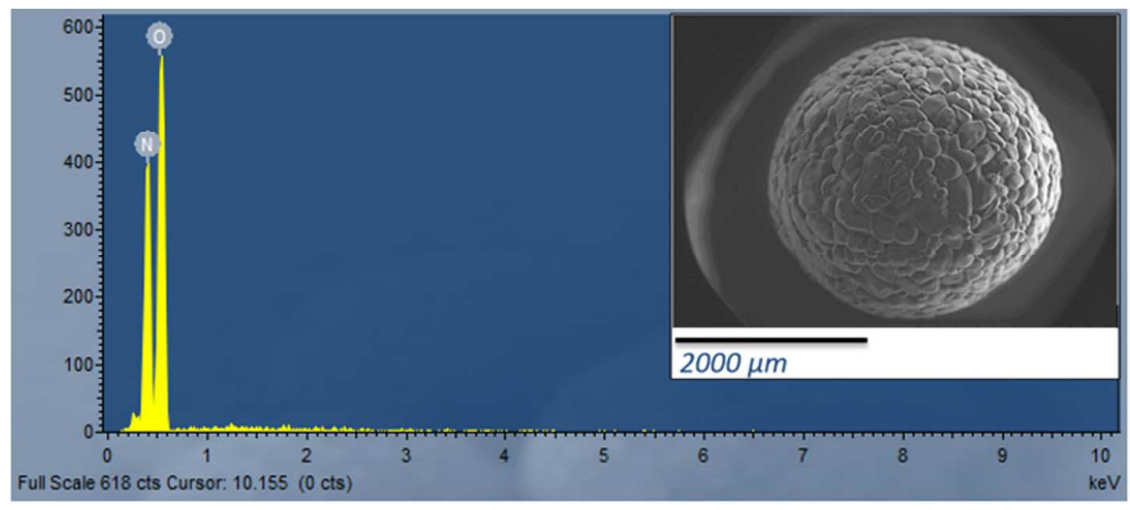

A typical EDS spectrum of the ground AN particles mixed with aluminium is shown in Figure S-3; the expected nitrogen, oxygen and aluminium were readily detected. As these ground particles were naturally smaller than the unground AN prills, carbon was present in most spectra (even when a lower voltage beam of $<10 \mathrm{keV}$ was applied). The provenance of carbon could have been the adhesive carbon disc placed upon the aluminium SEM pin stubs or contaminant interference accumulated during the prill grinding process. Subsequently, and moreover due to the presence of the aluminium flakes on the AN particle surfaces, the atomic ratio percentages of N:O, found now to be approximately $1: 1$ (18.5 at. \% of $\mathrm{N}$ and 19 at. \% of O) was inconsistent with the theoretical ratio of $2: 3$, augmented possibly by the presence of carbon (11.9 at. \%) from the adhesive carbon disc (not detected previously in the whole AN prill (Figure S-2)). The average atomic percentage of aluminium detected from particles was $50 \%$.

Figure S-3. Representative EDS spectrum of AlAN particles (AN particles ground and mixed with flaked Al; SEM micrograph inset).




The post-blast particles focused upon during analysis were those which contained principally nitrogen, oxygen and aluminium (and carbon as it was present in the spectra of the undetonated particles). On average, similar elemental ratios were detected from particles retrieved at all sampled distances, however the average amounts of nitrogen and oxygen detected in post-blast samples was approximately double that detected in the undetonated particles. This was likely due to less aluminium being present in the post-blast particles. As exhibited by the micrographs in the main text (Figure 2), little, if any, aluminium presence was indicated in post-blast AlAN particles, the EDS analysis also showed lower amounts of aluminium $(\sim 23$ at. \%) was detected from the post-blast particles compared to the undetonated material ( $\sim 50$ at. \%) (Table S-1). This would have caused the amounts of nitrogen and oxygen detected from each particle to be greater. The post-blast elemental composition ratios were therefore not comparable to that of the undetonated AlAN.

Table S-1. Average atomic percentage of elements (normalised without carbon) detected from EDS analysis of particles recovered $1 \mathrm{~m}, 2 \mathrm{~m}$ to $3 \mathrm{~m}$ and $4 \mathrm{~m}$ to $7 \mathrm{~m}$ from the charge centre of AlAN firings (given to 2 significant figures) compared to undetonated AlAN particles (also normalised without $\mathrm{C}$ ). $\mathrm{N}=$ range of $11-217$ particles for distance range of $1 \mathrm{~m}$ to $7 \mathrm{~m}$.

\begin{tabular}{llll}
\hline Distance from detonation & N (at. \%) & O (at. \%) & Al (at. \%) \\
\hline $1 \mathrm{~m}$ & $37 \pm 9.6$ & $38 \pm 10$ & $23 \pm 10$ \\
2 and $3 \mathrm{~m}$ & $39 \pm 8.6$ & $43 \pm 9.6$ & $24 \pm 13$ \\
4 to $7 \mathrm{~m}$ & $26 \pm 15$ & $40 \pm 14$ & $21 \pm 11$ \\
Undetonated particles & $21 \pm 6.2$ & $22 \pm 7.9$ & $57 \pm 9.4$ \\
\hline
\end{tabular}

\section{Raman Spectroscopy}

The chemical features of prominent Raman bands associated with the ammonium nitrate of Figure 3 in the main manuscript (inserted again below) are provided in Table S-2.

Figure 3 (from main manuscript). Raman spectrum of pre-blast AlAN particles (black spectrum) compared to representative spectra of post-blast particles collected at $1 \mathrm{~m}$ (red spectrum), $2 \mathrm{~m}$ to $3 \mathrm{~m}$ (blue spectrum), and $4 \mathrm{~m}$ to $7 \mathrm{~m}$ (pink spectrum) from the detonations. The green spectrum is of the adhesive carbon background.




Table S-2. Chemical feature of Raman bands detected from pre- and post-blast AlAN particles.

\begin{tabular}{ll}
\hline Raman shift $/ \mathbf{c m}^{-1}$ & Feature \\
\hline$\sim 200$ & Lattice vibrations of the $\mathrm{NO}_{3}{ }^{-}$and $\mathrm{NH}_{4}{ }^{+}$ions \\
$\sim 715$ & In-plane bending vibrations of the $\mathrm{NO}_{3}{ }^{-}$ion \\
$\sim 1040$ & Symmetric stretching vibration of the $\mathrm{NO}_{3}{ }^{-}$ion \\
$\sim 1300$ & Weaker bands due to symmetric $\mathrm{N}-\mathrm{O}$ stretches \\
$\sim 1400$ & Stretching vibration of $\mathrm{NO}_{3}^{-}$ \\
\hline
\end{tabular}

\section{Section 3. Plastic Explosive No. 4}

\section{EDS analysis}

The EDS analysis of undetonated PE4 showed the elemental composition of the pre-blast material to consist of only carbon, nitrogen and oxygen as expected with no other elemental contaminants present. The theoretical ratio of $\mathrm{C}: \mathrm{N}: \mathrm{O}$ in $\mathrm{RDX}(1: 2: 2)$ was not however reflected in the majority of spectra (typical spectrum shown in Figure S-4); the greater intensity of the carbon signal from the PE4 particles was likely due to the plasticizer (pentaerythritol dioleate) binding the explosive crystals together as well as the detection of carbon from the double-sided adhesive disc that was on the Al stubs.

Figure S-4. EDS spectrum of PE4 (RDX based explosive composition) showing elemental composition of C (at. \% of 33), N (at. \% of 30.6) and O (at. \% of 36.4). This spectrum was representative of multiple PE4 particles analysed via EDS (a representative micrograph of which is inset).



The elemental compositions of the particles ascribed to be post-blast PE4 residue were consistent with the undetonated material in that, overall, the only elements detected from them were $\mathrm{C}, \mathrm{N}$ and $\mathrm{O}$. However, the detected atomic percentages of the elements varied from that of the pre-blast material, where the ratio of $\mathrm{C}, \mathrm{N}$ and $\mathrm{O}$ was almost 1:1:1; on average no such consistent elemental atomic ratio was found for the post-blast particles. The carbon signal detected from the post-blast particles at each grouped distance was the strongest (Table S-3) and the nitrogen signals were the weakest, the greatest intensities of which were detected from the largest particles (those recovered at $2 \mathrm{~m}$ and $3 \mathrm{~m}$ from the detonations). 
Table S-3. Average atomic percentage of elements detected from EDS analysis of particles recovered $1 \mathrm{~m}, 2 \mathrm{~m} \& 3 \mathrm{~m}$, and $4 \mathrm{~m} \& 5 \mathrm{~m}$ from the charge centre of PE4 firings (given to 2 significant figures) compared to undetonated PE4 particles. $\mathrm{N}=$ range of $3-98$ particles for distance range of $1 \mathrm{~m}$ to $5 \mathrm{~m}$.

\begin{tabular}{llll}
\hline Distance from detonation & $\mathbf{C}($ at. $\%)$ & $\mathbf{N}($ at. $\%)$ & $\mathbf{O}($ at. $\%)$ \\
\hline $1 \mathrm{~m}$ & $61 \pm 11$ & $10 \pm 3.2$ & $29 \pm 9.8$ \\
2 and $3 \mathrm{~m}$ & $51 \pm 6.1$ & $18 \pm 5.9$ & $31 \pm 10$ \\
4 and $5 \mathrm{~m}$ & $63 \pm 6.1$ & $40 \pm 14$ & $21 \pm 11$ \\
Undetonated particles & $31 \pm 6.2$ & $27 \pm 2.1$ & $35 \pm 5.1$ \\
\hline
\end{tabular}

\section{FIB- SEM: Internal morphology of post-blast PE4 particles}

Figures S-5 and S-6 show higher magnification images of the internal structure of the post-blast PE4 particles, namely the vertically aligned column of approximately 100 to $150 \mathrm{~nm}$ thickness.

Figure S-5. Internal structure of FIB milled particle found at $2 \mathrm{~m}$ from the detonation of a $0.5 \mathrm{~kg}$ PE4 charge showing the vertically aligned columns, or rods, within.

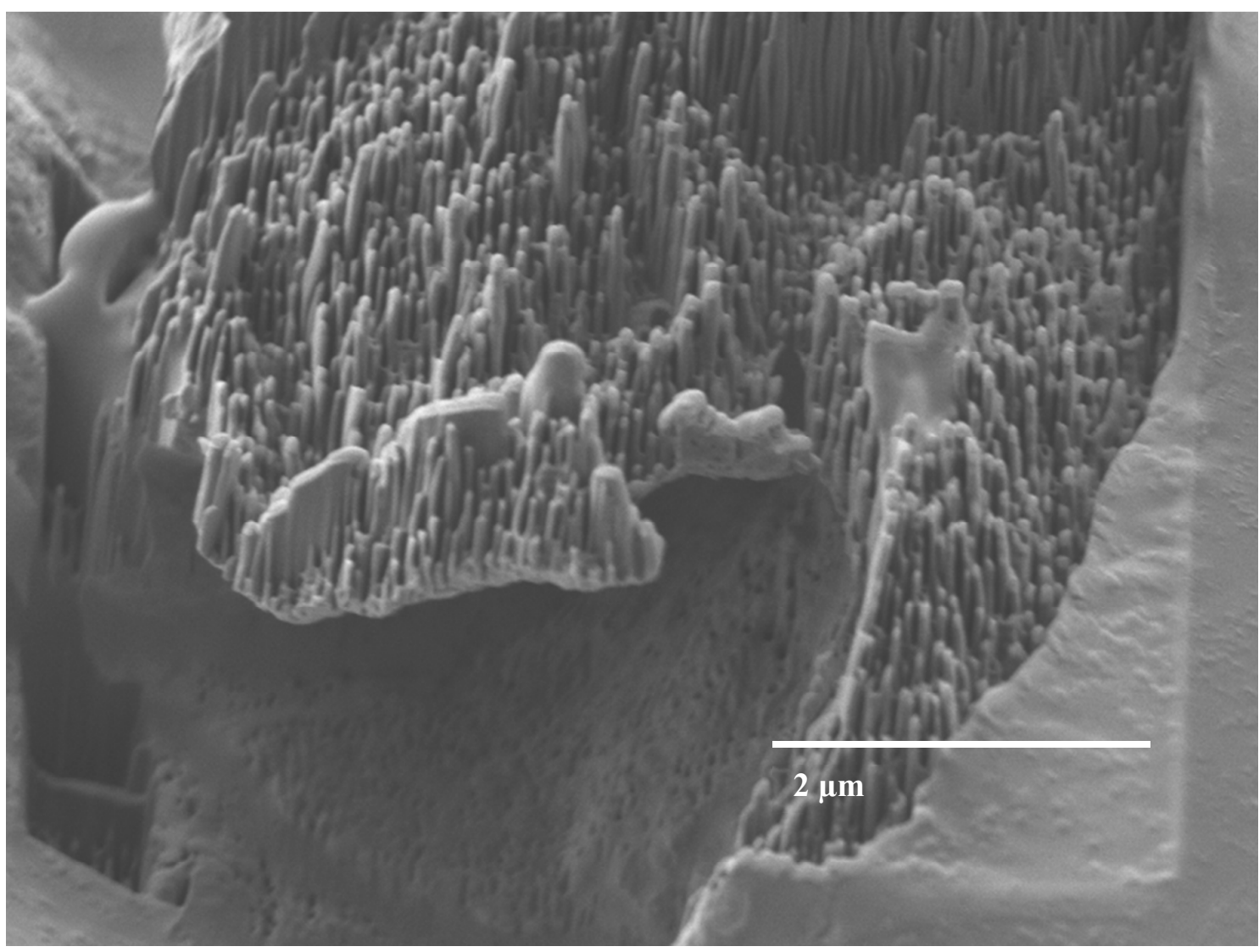


Figure S-6. Side-on view of the internal columns of post-blast PE4 particles, labelled thicknesses are of $126.9 \mathrm{~nm}$ (left) and $158.6 \mathrm{~nm}$ (right).

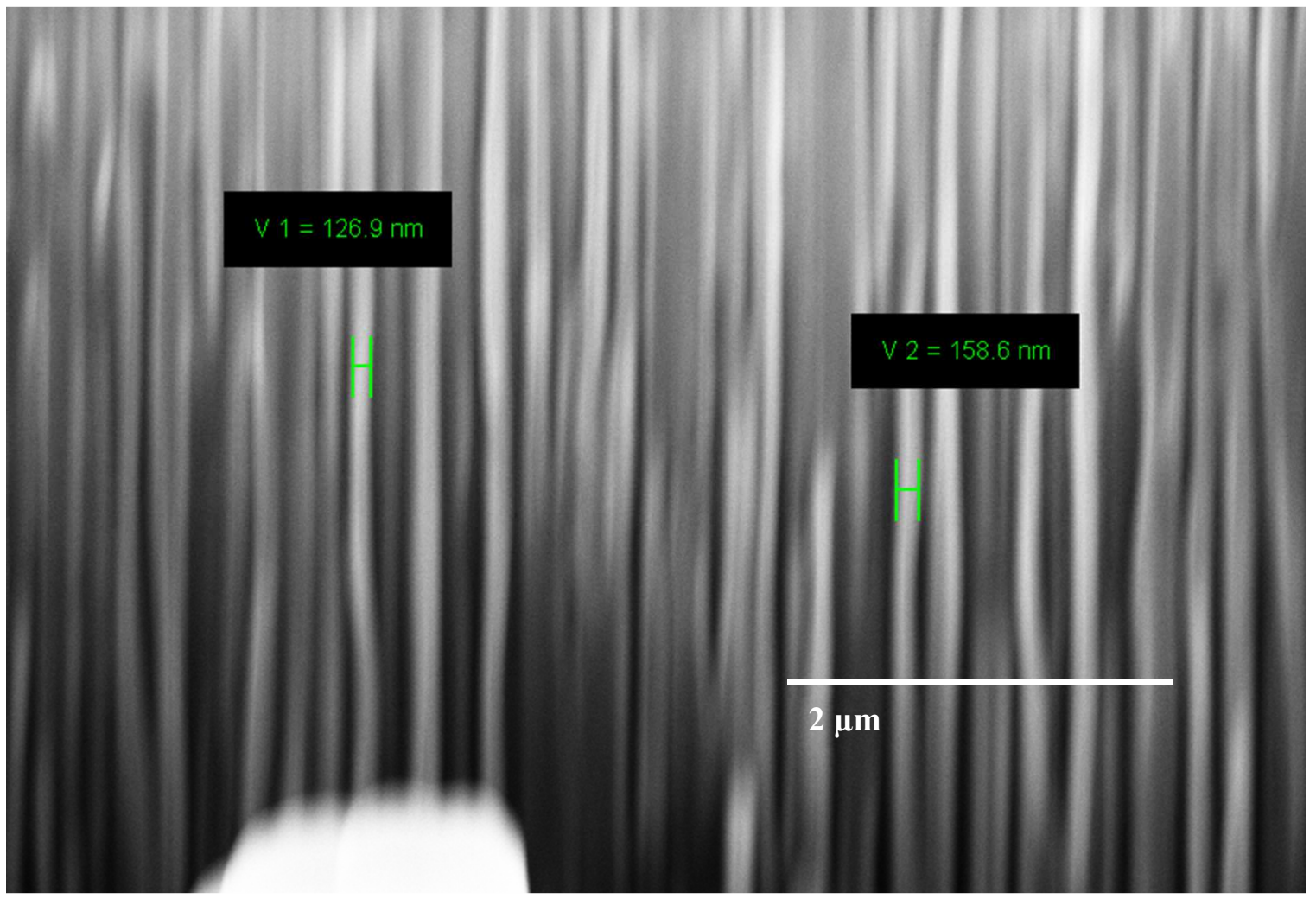

\section{HPLC-MS of post-blast PE4 particles}

The MeV-SIMS analysis presented in the main manuscript proffered a new method for detecting explosive residues on surfaces, and whilst successful in this original application of the technique, due to interference from the stub backgrounds the analysis was not completely conclusive.

In order to verify the presence of RDX on stub surfaces, each was washed in $5 \mathrm{~cm}^{3}$ of acetone, the extract filtered through $0.2 \mu \mathrm{m}$ nylon filters and allowed to evaporate. The residual material in the vials was reconstituted in $1.8 \mathrm{~cm}^{3}$ of MeCN and analysed with HPLC-MS. The samples were spiked with $0.1 \% \mathrm{CHCl}_{3}$ in order to produce the $\left[\mathrm{M}+{ }^{35} \mathrm{Cl}\right]^{-}$and $\left[\mathrm{M}+{ }^{37} \mathrm{Cl}\right]^{-}$adducts that are more amenable to electrospray ionisation compared to the RDX molecule alone.

The instrument operating conditions for the HPLC and the MS are as provided in the main text. The chromatogram in Figure S-7 is representative of samples containing RDX. 
Figure S-7. Reconstructed ion chromatogram for RDX $(\mathrm{m} / \mathrm{z} 256.91)$. The retention time of the analyte was 2.4 minutes and the strongest signal intensity generated was $5.74 \times 10^{6}$. Separation was achieved on a $2.1 \mathrm{~mm}$ (i.d.) x $50 \mathrm{~mm}, \mathrm{C} 18(1.7 \mu \mathrm{m}, 130 \AA)$ column at a flow rate of $200 \mu \mathrm{L} / \mathrm{min}$. The total sample run time was 10 minutes.

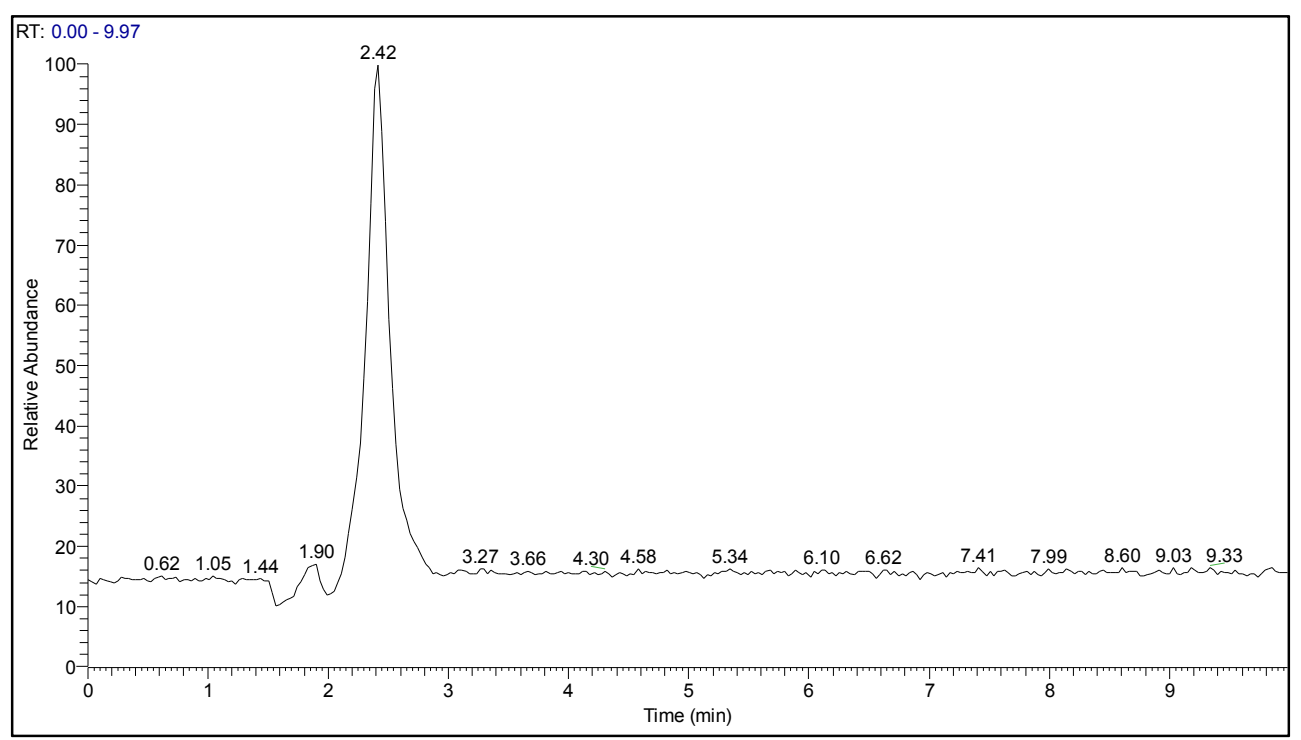

The corresponding mass spectra of the ions at $m / z \sim 257$ and $m / z \sim 259$ (adducts of either [RDX $\left.+{ }^{35} \mathrm{Cl}\right]^{-}$ or $\left.\left[\mathrm{RDX}+{ }^{37} \mathrm{Cl}\right]^{-}\right)$is shown in Figure S-8.

$\mathrm{MS}^{2}$ experiments on the $\left[\mathrm{M}+{ }^{35} \mathrm{Cl}\right]^{-}(\mathrm{m} / z$ 256.94) produced fragment ions of $\mathrm{m} / \mathrm{z} 226.98$ and $\mathrm{m} / \mathrm{z}$ 198.00 (Figure S-9) corresponding to $\left[\mathrm{M}+{ }^{35} \mathrm{Cl}-30\right]^{-}$and to $\left[\mathrm{C}_{3} \mathrm{H}_{6} \mathrm{~N}_{5} \mathrm{O}_{3}+{ }^{37} \mathrm{Cl}\right]^{-}$, respectively.

Figure S-8. Mass spectrum of peak at retention time of 2.41 (from Figure S-7). Selected ion monitoring scan collision energy was 35 , spray voltage $5 \mathrm{kV}$, spray current $30 \mu \mathrm{A}$, sheath and auxiliary gases had flow rates of 30 and 10 , capillary temperature $275^{\circ} \mathrm{C}$. Isolation widths were 2.00 and scans consisted of 5 averaged 'micro-scans' per scan event, each with a maximum injection time of $200 \mathrm{~ms}$. The presence of ions of $\mathrm{m} / z 257$ and $\mathrm{m} / \mathrm{z} 259$ confirm the presence of RDX (RDX and Cl adducts).

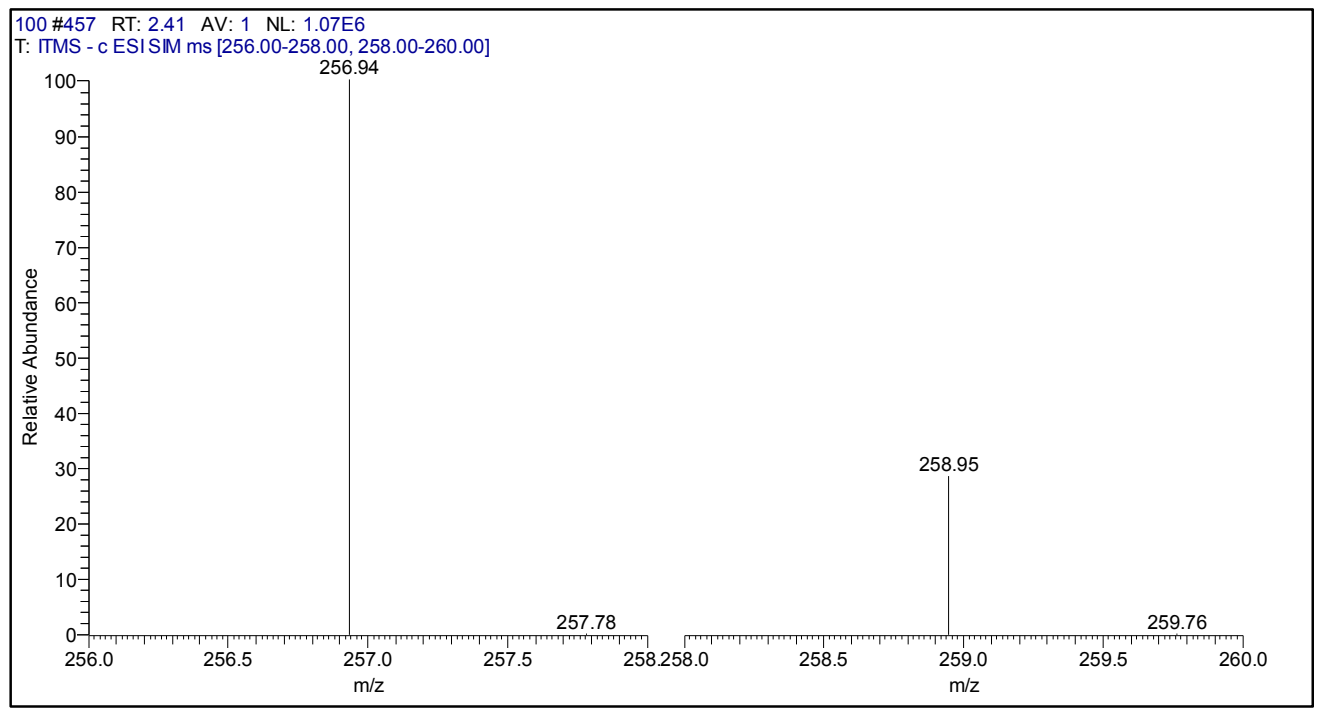


Figure S-9. MS/MS spectrum of m/z 256.94 ion with product ions at m/z 226.98 and m/z 198.00 . Spectrum collected with collision energy of 35.0, isolation widths of 2.00 , and consisting of 3 averaged micro-scans each of maximum injection time of $200 \mathrm{~ms}$.

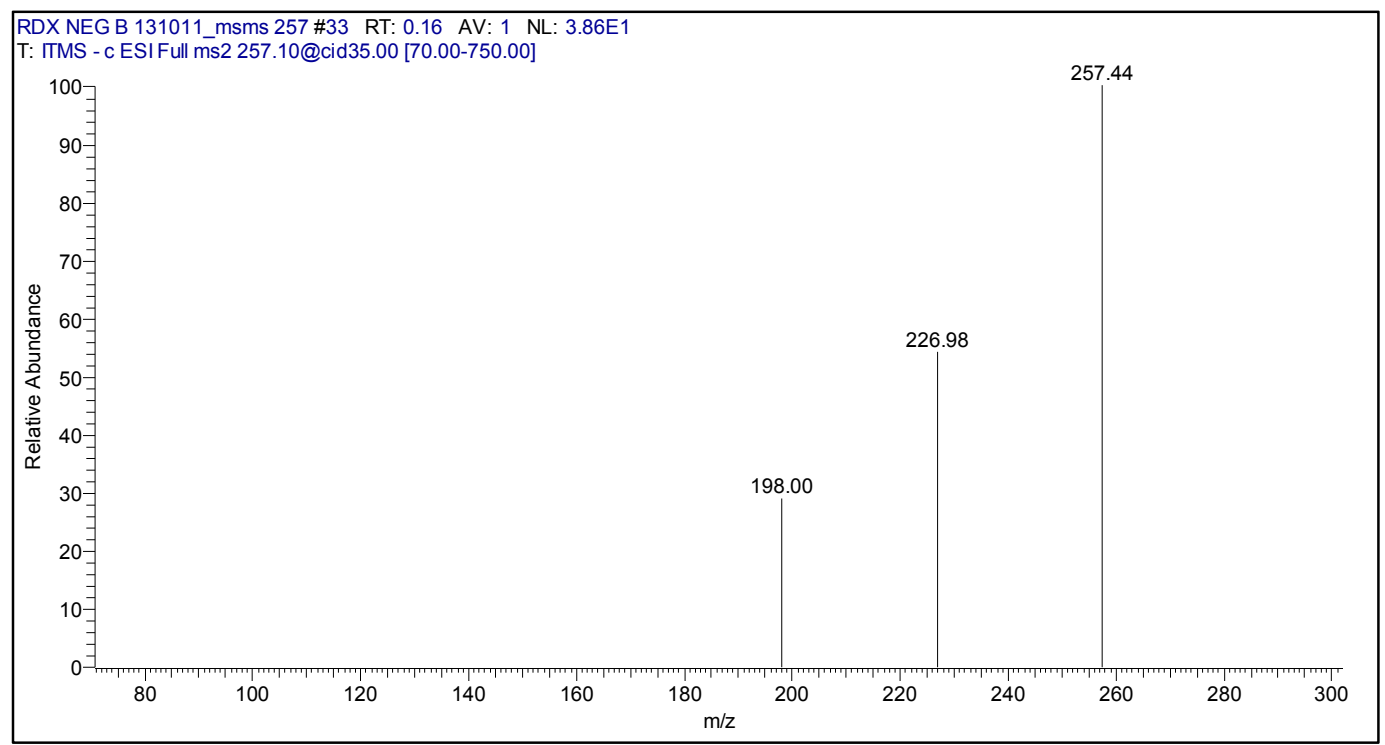

\section{Section 4. Quantification of Post-blast Explosive Residues}

\section{Particle size distribution}

SEM stubs were scanned across the surface during analysis to ensure that all relevant particles ascribed to be explosive matter were counted, and the sizes of them (diameter of each) recorded. Attempts to analyse this data statistically was problematic due to the impracticalities of collecting substantial quantities of post-blast explosive residue, firstly due to the fact that very little of it is formed in the first instance, and secondly because the surface areas upon which the samples were collected were naturally small due to the requirement that they fit within an SEM chamber. Additionally, a valid comparison between particle sizes would require consistency in particle shapes, i.e. for them all to be spheroidal, or cubic, etc., and as this was not the case it is important to note that any statistical interpretations made herein are limited to such caveats.

The mean average particle diameters from each sampled distance are presented in Table S-4; for AlAN, the average particle sizes increased with increasing distance from the detonations, this was less obvious for the post-blast PE4 particles, which decreased in size after $3 \mathrm{~m}$. Due to wide variability in the particle sizes however, as indicated by the standard deviations in Tale S-4, the mean average was not deemed a useful indicator of particle size. A more meaningful measure of comparison was the average particle diameter ranges that are provided in the main text.

Figure S-10 shows the particle size distributions (in $50 \mu \mathrm{m}$ intervals) at different distances from the AlAN and PE4 detonations; the recorded number of particles in these diameter bins was used to determine the significance of the relationship between the particle sizes and distance from detonation at a $95 \%$ confidence level. In the case of both explosive formulations, a significant relationship was found (calculated p-value $<0.0001$ for AlAN data and 0.005 for PE4 data), allowing the distance to be used as a discriminant factor for the estimation of particle size distribution (or vice-versa). Whilst these preliminary statistical findings are indicative herein of a particle size-distance relationship, further experiments that can capture more particles (i.e. increase the representative number of particles) are required to conclusively determine the correlation. Furthermore, the data used for the calculations excluded the smeared (or flattened) particles observed on some stubs, in particular at the 
$1 \mathrm{~m}$ distances following the AlAN firings. It was unclear how many discrete particles were within these smears, and to treat each smeared deposited as ' 1 ' whole particle would have been inaccurate and a cause of data skewing.

Table S-4. Mean average number of particles found at each sampled distance from the detonations. The number of particles found per firing was based on the total amount of particles observed at each distance (i.e. the sum of particles observed on the 4 stubs positioned at each distance around the detonations).

\begin{tabular}{ccccc}
\hline Distance from centre (m) & \multicolumn{2}{c}{ Total particle count per distance } & \multicolumn{2}{c}{ Mean average diameter $(\boldsymbol{\mu m})$} \\
\hline & AlAN & PE4 & AlAN & PE4 \\
\hline 1 & 247 & 132 & $98( \pm 53)$ & $81( \pm 64)$ \\
2 & 317 & 129 & $147( \pm 57)$ & $142( \pm 57)$ \\
3 & 98 & 82 & $137( \pm 66)$ & $118( \pm 49)$ \\
4 & 115 & 22 & $230( \pm 109)$ & $44( \pm 25)$ \\
5 & 53 & 9 & $216( \pm 105)$ & $31( \pm 23)$ \\
6 & 27 & 0 & $194( \pm 78)$ & - \\
7 & 11 & 0 & $248( \pm 117)$ & - \\
10 & 0 & 0 & - & - \\
\hline
\end{tabular}

Figure S-10. Particle size distributions of post-blast explosive residues observed on SEM stubs at different distances from AlAN (A) and PE4 (B) detonations. The sizes were recorded in $50 \mu \mathrm{m}$ diameter intervals.






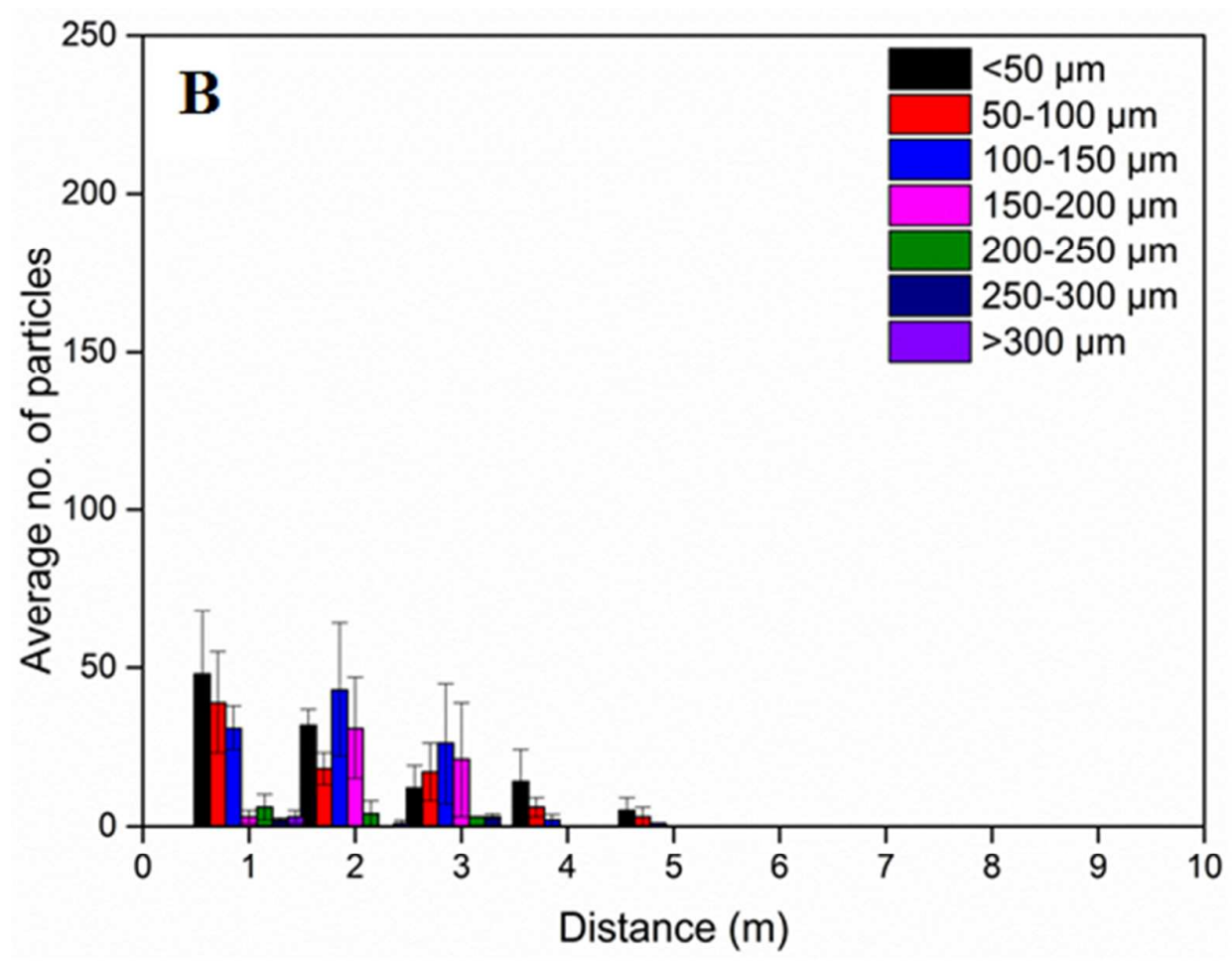

\section{Chromatographic quantification of residues}

Without knowledge of the density of every particle, it was not possible to quantify the mass of deposited explosive, in either the AlAN or PE4 case, by counting the number of particles present on the SEM stubs. Residue were therefore washed off of the stub surfaces by placing each in $5 \mathrm{~cm}^{3}$ of 18 $\mathrm{M} \Omega$ deionized water and acetone for the AlAN and PE4 residues respectively. The resulting solutions were filtered through $0.2 \mu \mathrm{m}$ nylon pores and the extracts analysed chromatographically. Prior to washing, attempts to remove obvious, large sediment particles from stubs (particularly those at $1 \mathrm{~m}$ from the detonations) were made with fine-pointed sterile tweezers.

Inorganic residues were analysed on a Dionex ICS-2000 reagent free IC system (as detailed in the main text method). In order to attempt to quantify the ions in the post-blast samples, ten series calibration standards $(1 \mu \mathrm{g} / \mathrm{L}$ to $1000 \mu \mathrm{g} / \mathrm{L})$ of nitrate and ammonium were prepared in deionised water (DI) (18 M $)$ ) via serial dilution of a stock solution. Errors in standard preparation were controlled by making and injecting multiple standards of the same concentrations (i.e. repeats) to ensure that errors were not amplified through the calibration series by confirming consistent peak areas were produced by each sample of standard at the same concentration.

The calibration produced $\mathrm{R}^{2}$ values of 0.9207 and 0.8458 for the nitrate and ammonium respectively. The limits of quantification for the nitrate and ammonium using the system conditions were $0.1 \mathrm{mg} / \mathrm{L}$ and $0.5 \mathrm{mg} / \mathrm{L}$ respectively (the number of data points used in the calibration that were above the LOQ were 9 and 6 for the nitrate and ammonium respectively). Blank samples of DI water were injected prior to the sequence to check the quantities of target analytes present in the solvent at a background level and these were subtracted from test sample data. Any samples in which the concentration of ammonium or nitrate was greater than the maximum data point on the calibration $(1000 \mu \mathrm{g} / \mathrm{L})$ were reinjected after suitable dilution (typically by factors of $20,10,5$ or 2).

The masses of $\mathrm{NH}_{4}{ }^{+}$and $\mathrm{NO}_{3}{ }^{-}$were a stoichiometric $1: 1$ ratio in the majority of cases. Nonstoichiometric quantities of the analytes were detected however in some of the post-blast samples 
retrieved from $1 \mathrm{~m}$. Lower levels of ammonium were detected compared to nitrate, potentially due to ion suppression of high concentrations of the $\mathrm{NH}_{4}{ }^{+}$cation, which is known to occur when using a suppressed conductivity detector ${ }^{(a)}$. Non-stoichiometric $\mathrm{NH}_{4}{ }^{+}: \mathrm{NO}_{3}{ }^{-}$ratios have been detected in postblast samples from previous studies ${ }^{(b)}$; the mass of post-blast AN from such samples herein was dealt with by adding the measured stoichiometric (1:1) amount of ammonium to nitrate ions, i.e. the lower quantity ion $\left(\mathrm{NH}_{4}{ }^{+}\right)$and equivalent $\mathrm{NO}_{3}{ }^{-}$amount, therefore it is possible that the total mass amounts in these cases were underestimated due to discounting the 'excess' nitrate detected. This was deemed more appropriate than overestimating the $\mathrm{NH}_{4}^{+}$that was not detected, but importantly, renders the quantification approximate rather than definitive.

RDX was separated on Dionex UltiMate 3000 single capillary LC system using an Acquity BEH C-18 column as described in the main text. All control and test samples were spiked with $0.1 \% \mathrm{CHCl}_{3}$ in order to form $\left[\mathrm{M}+{ }^{35} \mathrm{Cl}\right]^{-}$and $\left[\mathrm{M}+{ }^{37} \mathrm{Cl}\right]^{-}$adducts amenable to ESI-MS detection. A set of reference standards of concentrations between $1 \mu \mathrm{g} / \mathrm{L}$ to $1000 \mu \mathrm{g} / \mathrm{L}$ of $\mathrm{RDX}$ in $\mathrm{MeCN}$ were made using a stock solution of RDX in order to quantify the post-blast residues. The calibration produced an $\mathrm{R}^{2}$ of 0.9958 . The limit of quantification for RDX using the system conditions was $0.01 \mathrm{mg} / \mathrm{L}$ (the number of data points used in the calibration that were above the LOQ were 8).

Figure S-11 shows that the average amount of ammonium nitrate detected at each sampled distance (based on the six repeated firings of AlAN) decreased with increasing distance from the central firing area. The same trend was observed for RDX, although much lower quantities were detected. Each value in the figure is the summed amount of explosive detected of four samples (from the four sampled orientations) at each distance from the detonation.

Figure S-11. Ammonium nitrate and RDX residues ( $\mu \mathrm{g})$ detected on stub surfaces at incremental distances from the detonations of $0.5 \mathrm{~kg}$ AlAN and $0.5 \mathrm{~kg}$ PE4 charges, determined using IC and HPLC-MS respectively. Each value is the summed amount of explosive detected from samples positioned in four orientations around the charge centre at each incremental distance, with the error bars indicating the standard deviation of the mean average amount based on 6 firings of each charge.

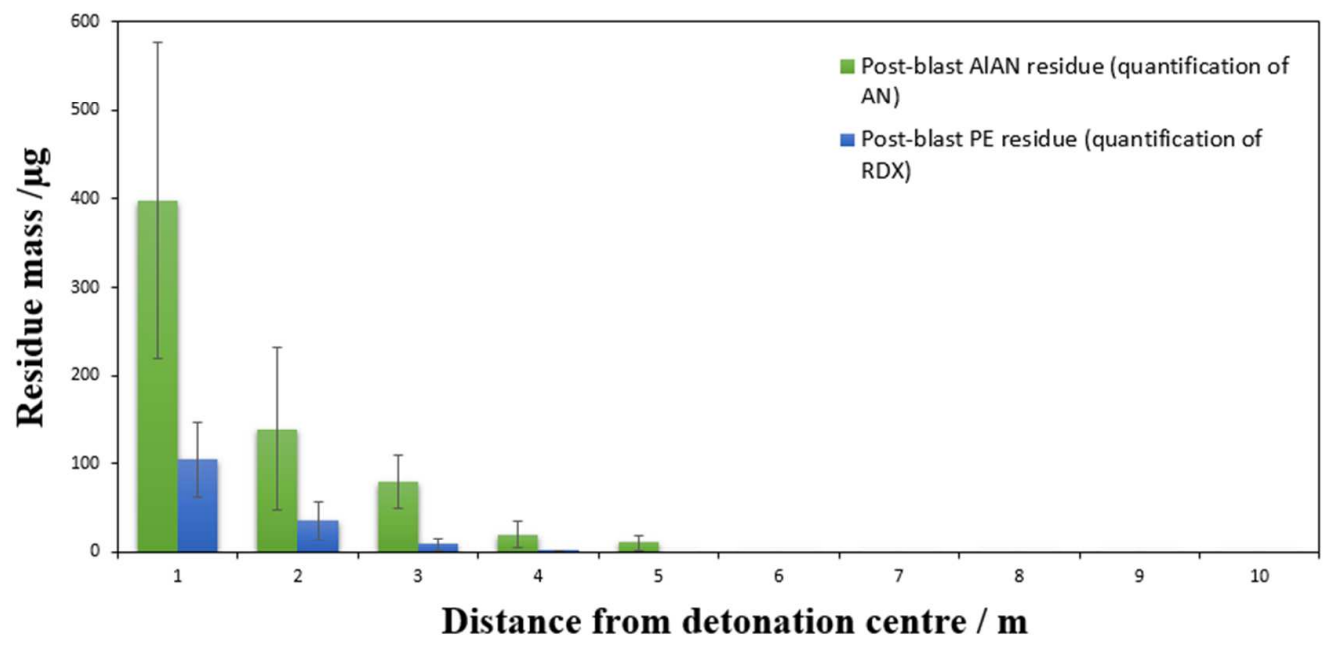

\footnotetext{
a Johns, C., Shellie, R. A., Potter, O. G., O’Reilly, J. W., Hutchinson, J. P. \& Guijt, R. M. J. Chrom. A, 1182, 2008. Weiss, J. Dionex Environmental Report, June 2011.

${ }^{\mathrm{b}}$ Cullum, H., Lowe, A., Marshall, M. \& Hubbard, P. J. Fors. Sci. 45, 2000.

Phillips, S., Lowe, A., Marshall, M., Hubbard, P., Burmeister, S. G. \& Williams, D. RJ. Fors. Sci. 45, 2000. Monsfield, A. M., Marshall, M., Walker, C. L. \& Hubbard, P. J. Fors. Sci. 46, 2001.
} 
The error bars on Figure S-11 show that despite the repeated firings being of the same charge mass and configurations under the same conditions, the residual amounts of undetonated residue detected around each explosion varied in quantity, signifying the unique nature of each detonation event. The same distribution pattern however, of fewer residues detected with increasing distance from the detonation centre, was observed, which concurs with the current forensic practice of targeting the area surrounding the blast region for key forensic evidence ${ }^{(\mathrm{c})}$.These findings develop our understanding of the dynamics of post-blast explosive particles and offer the means to not only provide indications of the explosive used and the location of the detonation, but also enable evidence collection to be more targeted.

Although the quantification cannot be correlated exactly to the number of particles present on the stub surfaces, the trends in the data generated from chromatographic analysis seemed to correspond to those found using the SEM. However, post-blast particles were observed on stubs up to than $7 \mathrm{~m}$ and $5 \mathrm{~m}$ from the firings, but were detected up to only $5 \mathrm{~m}$ and $3 \mathrm{~m}$ for the AlAN and PE4 explosives respectively. The limits of detection for nitrate $(0.1 \mathrm{mg} / \mathrm{L})$, ammonium $(0.5 \mathrm{mg} / \mathrm{L})$, and RDX $(0.1$ $\mathrm{mg} / \mathrm{L}$ ) should have allowed the detection of the observed particles; the reason for not detecting the explosive residue from these further positioned samples sites is unknown. It is possible that in the case of RDX, interference due to the potentially co-extracted adhesive from the carbon disc on the SEM stubs, may have affected. Whilst these distributions trends are limited to the small SEM stub surfaces and discrete sampling positions used in these experiments, previous studies have also found the majority of explosive residue to be deposited within $5 \mathrm{~m}$ from detonations with little or no material found at a greater distance ${ }^{(\mathrm{d}, \mathrm{e}, \mathrm{f})}$. The application of more sensitive analytical tools further from the detonation centre would be required in real case work to detect trace explosive material further from the explosion seat or centre.

The production of more post-blast residual explosive material from the AlAN charges (maximum total mass of AN detected $=594 \mu \mathrm{g}$ ) compared to PE4 (maximum total mass of RDX detected $=176 \mu \mathrm{g}$ ) may be due to the slower energy release process of the more non-ideal ${ }^{(\mathrm{g})} \mathrm{AlAN}$ formulation compared to the more efficient unimolecular military composition that would generate fewer residues. Alternatively, although efforts were made to remove obvious sediment with tweezers prior to washing the stubs, it would not have been possible to remove all (in particular smaller) sediment particles that may subsequently have contributed to the detection of ammonium and nitrate on the surfaces, thus potentially producing the seemingly higher quantities of AN seen in Figure S-11. On the other hand, there is no guarantee that this sediment removal did not also detach any post-blast residual material generated during these experiments that may have adhered to, or been beneath, such larger sediment particles. Without being able to control or conclusively differentiate between the contribution of ammonium and nitrate from the explosive and that from any remaining sediment (and the potential

\footnotetext{
' J. C. Pennington, T. F. Jenkins, G. Ampleman, S. Thiboutot, J. M. Brannon, A. D. Hewitt, J. Lewis, S. Brochu, E. Diaz, M. R. Walsh, M. E. Walsh, S. Taylor, J. C. Lynch, J. Clausen, T. A. Ranney, T. A. Ramsey, C. A. Hayes, C. L. Grant, C. M. Collins, S. R. Bigl, S. Yost, K. Dontsova, Engineer Research and Development Centre, 2006.

${ }^{d}$ E. I. V van den Hengel, R. J. A. Kersten, F. A. M. H. Jacobs, R. Oostdam, N. H. A. Versloot, in IChemE Sympos. Series, No. 153, Edinburgh, UK, 2007

${ }^{\mathrm{e}}$ N. Abdul-Karim, R. Morgan, R. Binions, T. Temple, K. Harrison, J. Forensic Sci. 2013, 58, 365.

${ }^{\mathrm{f}}$ I. V. Schweigert, J. Phys. Chem. A 2015, 119, 2747.

${ }^{g}$ Most solid explosives are 'non-ideal' in that they release some energy after the passage of the detonation front, usually in the form of afterburning of the detonation products with atmospheric oxygen. This heat of combustion contributes to the later energy release and occurs more so for the thermobaric AlAN charges used herein (due to the combustion of aluminium particles) than for the PE4. (C. E. Needham. Blast Waves, Springer-Verlag Berlin Heidelberg (2010)).
} 
underestimation of the some of the AN detected in samples at $1 \mathrm{~m}$ due to cation suppression), a robust interpretation of these current results is not possible.

Additionally, the soil on the firing range site was likely contaminated with explosive residues from previous firing trials (the level of contamination is unknown as no control soil samples could be taken during these current trials) and may have contributed to the detection of both explosive types on the stub surfaces. Although at a $2 \mathrm{~m}$ sampling height it is unlikely that this was a dominating effect (and moreover because the number of explosive particles observed was always greater than the amount of sediment particles observed), it further limits the accuracy of the quantitative analysis herein. Neither particle counting techniques nor solvent washing/chromatographic analyses are solutions to this particular residue quantification problem; the first is semi-quantitative, the latter fraught with contamination and/or error issues, particularly when using such small sampling areas. Ideally, a method to directly quantify the mass of each explosive particle is required, coupled with techniques to eradicate the possibility of sediment contamination, for example by obtaining access to firing range that allows a fire-proof tarpaulin to be placed on the firing pad or using a 'fresh' site in the first instance. 